
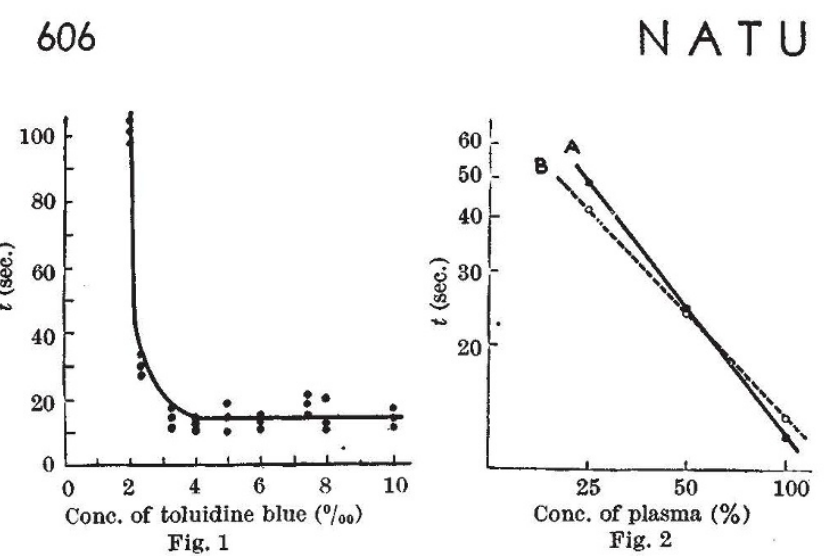

proportion as in the case of the coagulation with thromboplastin and calcium (curve B, Fig. 2).

These experiments show that it is possible to produce coagulation of decalcified plasma without addition of calcium by adding toluidine blue only. The preformed plasma-thromboplastin is active enough to produce coagulation of the blood if the action of the heparin complex is inhibited by toluidine blue. The heparin present in blood takes part also in the blood-clotting process, and the role of that physiological amount of heparin seems to be to maintain the fluidity of blood in the vessels.

Department of General Physiology, JAROMÍR MYSLIVEČ́E

Charles University, Prague. Oct. 11.

${ }^{1}$ Feissly, R., and Enowicz, M., J. Suisse de Med., 76, 274 (1946). 'Willander, O., Skand. Arch. Physiol., Suppl. 15, 81 (1939).

s Jorpes, J: E., "Heparin" (London, 1946).

\section{Nature of a Muscle-Inhibiting Compound in Lucerne and its Possible Connexion with Bloat in Cattle}

IN an earlier note ${ }^{1}$ attention was directed to the muscle-inhibiting power of clover juice and a possible relationship between this action and the disturbance known as bloat, or hoven, in cattle. Further work on a variety of herbage plant juices has confirmed the early findings ${ }^{2}$, and has led to the separation from lucerne juice, purification and probable chemical identification, of a substance capable of inhibiting muscle movement.

Hydrocyanic acid can cause smooth muscle paralysis, and undoubtedly some acid is produced in the rumen of cattle grazing legumes, by the hydrolysis of cyanogenetic glycosides. South African workers ${ }^{3}$, however, failed to incriminate hydrocyanic acid as a cause of acute bloat, but it should not be ruled out as one of possibly several aggravating or supplementing factors. This aspect has received attention at Aberystwyth 4 .

The compound we have isolated from lucerne, by ether extraction of clarified juice, is a pale-yellow crystalline substance which, after repeated crystallization, strongly inhibits muscle action. Chemical and physical examination has shown it to be a flavone, and, subject to final confirmation by synthesis, it is most probably $3^{\prime}, 4^{\prime}, 5$ trihydroxy, 7 methoxy flavone, a compound which, so far as is known, has not been previously reported as occurring naturally, although Kostanecki ${ }^{5}$ synthesized it by reduction of tetramethoxy luteolin.

Flavones occur widely in plant material, presumably as glycosides, and quercetin, $3^{\prime}, 4^{\prime}, 5,7$ tetra-
April 16, 1949 Vol. 163

hydroxy flavanol, for example, has been reported in white clover. Probably species and growing conditions determine the nature and quantity of the flavone present. Although a quantitative separation of the lucerne flavone could not be effected, there was little doubt that the young third-growth in August contained much less flavone than material grown earlier in the year.

Isolated muscle tests were made on thirty. four flavanoid compounds, most of them kindly supplied by Sir Robert Robinson. These all showed muscle-inhibiting action in concentra tions between 1/200,000 and 1/50,000. The influence of various substituent groups in the flavone molecule could not be judged with any reliability, since varying, and generally slight, solubility affected the results.

Our knowledge of the pharmacological actions of the flavones is not extensive. They are reported as diuretics, cardiac stimulants and vaso-constrictors ${ }^{6}$, and do not appear to be toxic. Their power to in hibit activity of isolated smooth muscle has been noted by Niahal?. They exhibit vitamin P-like activity, and rutin, a quercetin-rhamnoside, is being used therapeutically to decrease capillary fragility. The anti-oxidant action of vitamin P-like compounds towards adrenaline, which results in prolonged adrenaline effects on smooth muscle, have been confirmed with rutin, quercetin and the lucerne flavone, the rutin proving far less active than the flavones.

The significance, if any, of vitamin $\mathrm{P}$ in ruminant nutrition awaits elucidation, as also does the possibil. ity of flavones playing some part in bloat. Some preliminary tests have been made on sheep, feeding a flavone with and without potassium cyanide. Nothing of note has been achieved in these tests, apart from some inhibition of rumen movements by the cyanide. One difficulty complicating these tests has been the relative insolubility of the flavone. However, the trials will be repeated in the spring when the animals are grazing and ruminant conditions more closely approach those obtaining when bloat occurs.

W. S. Ferguson

DE B. AshwORTH

R. A. Terry

Imperial Chemical Industries, Ltd., Jealott's Hill Research Station, Bracknell, Berks.

Jan. 24.

${ }^{1}$ Ferguson, W. S., Nature, 161, 816 (1948)

2 Ferguson, W. S., Vet. Rec. (in the press).

${ }^{3}$ Clark, R., and Quin, J. I., Onderstepoort J., 20, 209 (1945).

4 Evans, E. T. R., and Evans, W. C., J. Brit. Grassland Soc., 3, 249 (1948). [See also Nature, March 5, p. 373.]

${ }^{5}$ Kostanecki, V., Ber., 34, 1452 (1901).

- Fukuda, T., Arch. exp. Path. Pharmakol., 164, 685 (1932).

${ }^{7}$ Mahal, H. S., Proc. Ind. Acad. Sci., 5B, 50, 186 (1937).

\section{Myosin and Actomyosin Content of the Heart-Muscle}

SZENT-GYöRGYI ${ }^{1-3}$ and his collaborators began their investigations on the contractile substances of muscle in 1941 ; my work on the myosin and actomyosin content of heart-muscle is mainly based on their results.

The extraction of actomyosin was carried out following the slightly modified method described by A. Csapó ${ }^{4}$ Pigs and rabbits were employed 